\title{
Об эволюции языка, внешнем воздействии и переводческой школе
}

Артем Мальгин

DOI: 10.30547/mediaalmanah.6.2020.164167

(c) Мальгин Артем Владимирович проректор по общим вопросам МГИМО,

координатор проектов российско-французского форума гражданских обществ «Трианонский диалог» в России (г. Москва, Россия), artemmalgin@gmail.com
Когда Поль де Синети формировал свою делегацию, он исходил из того, чтобы продемонстрировать опыт наших французских коллег, показать, сколь многому они научились, потому что франкофонная языковая среда, в отличие от русской, давно присутствует в пределах границ разных национальных государств. Франция и французский язык, казалось бы, уходили из сообществ (на разных континентах), в которых французский язык был родным, однако потом он снова прорастал, возвращался, формировались его особые варианты. Те, кто знает французский язык, наслаждаются его бельгийским и швейцарским вариантами или североафриканской логикой французского языка.

В этой связи хотелось бы выделить ряд практических моментов, актуальных для проблематики нашего семинара.

Во-первых, это эволюция языка внутри страны или региона, где язык не является родным для части населения, или билингвального региона. Именно в этой среде возникают достаточно серьезные угрозы и языку, и культурной идентичности, и, можетбыть, даже идентичности на политическом уровне. Важно было бы, в частности, посмотреть, как во Франции осуществляется мониторинг языковой ситуации в сообществах, которые, казалось бы, оторваны от языковой метрополии. В российском 


\title{
Evolution de la langue, influence extérieure et école de traduction
}

Artiom Malguine

\author{
(C) Malguine Artiom \\ vice-recteur du MGIMO pour les questions générales, coordinateur des projets réalisés en Russie \\ dans le cadre du forum franco-russe des sociétés civiles le « Dialogue de Trianon » \\ (Moscou, Russie), artemmalgin@gmail.com
}

Quand Paul de Sinety formait sa délégation, il partait de la volonté de montrer la meilleure expérience française dans le domaine où nos collègues français ont beaucoup appris, car l'environnement linguistique de la langue française, contrairement à celui du russe, existe depuis longtemps à l'intérieur des frontières des différents États nationaux. Depuis longtemps, il existe des communautés ayant comme langue maternelle le français qui se trouvent sur d'autres continents que la France. La France et le français semblaient avoir quitté ces communautés, mais ensuite le français refaisait surface, revenait pour s'affirmer dans des versions particulières. Il existe différentes versions de la langue française. Celui qui connaît le français se délectent des versions belge ou suisse, savourent le français parlé en Afrique du Nord où la langue évolue suivant sa propre logique, tout en gardant son lien avec la métropole linguistique. S'agissant de la langue russe, il existe aujourd'hui, en dehors de la Russie, deux grands foyers d'évolution de l'environnement russophone : l'Ukraine et la Biélorussie. D'autres communautés sont importantes, mais sont toutefois moins nombreuses que ces deux immenses foyers de la langue et de la culture russes.

Je voudrais souligner un certain nombre d'éléments pratiques dans le cadre de la problématique de ce séminaire.

Le premier est l'évolution de la langue à l'intérieur d'un pays, d'une région où la langue n'est pas maternelle pour une partie de la population, ou d'une région bilingue. C'est dans ces régions que des menaces assez sérieuses apparaissent pour la langue et l'identité culturelle, et peut-être pour l'identité au niveau politique. Il est important de voir comment est effectué en France le suivi de la situation linguistique dans des communautés qui semblent être détachées de la métropole linguistique. Prenons l'exemple des pays post-soviétiques. Nous avons ouvert une filiale de MGIMO en Ouzbékistan, je m'y rends assez souvent ces derniers temps et je vois qu'il y a beaucoup de russophones et de Russes là-bas, que l'environnement linguistique est présent, mais il s'agit d'une langue différente, qui évolue selon ses propres lois en matière de formation du lexique, du vocabulaire professionnel. Il est clair qu'on ne peut pas imposer des règles d'emploi de telles ou telles normes, mais il est possible que certaines limites puissent être tracées depuis la métropole linguistique. 
практике показателен пример постсоветских стран. В последнее время, бывая довольно часто в Узбекистане, где мы открыли филиал МГИМО, наблюдаю, что русскоязычного населения и русских в этой республике много, русскоязычная среда присутствует, но это иной язык, развивающийся по своим законам формирования лексики, профессионального вокабуляра. Понятно, что на расстоянии нельзя навязать стандарты использования тех или иных норм, но из языковой метрополии обозначить некие границы вполне возможно.

Во-вторых, язык подвергается внешнему воздействию и зачастую меняется не так, как бы нам хотелось. Он не может адаптироваться к целому ряду внешних влияний в узкопрофессиональных (особенно в быстроразвивающихся) сферах: банковской, финансовой, логистической. Эти области, к сожалению, остаются без внимания лингвистов. Обратитесь к специализированным СМИ, которые сегодня широко представлены в Интернете. Зачастую, чтобы перевести с русского на русский и убрать соответствующие жаргонизмы, которые нередко приходят из английского языка, требуются значительные усилия. Лингвистов, умеющих это делать, у нас не так много, поэтому модификация профессионального языка - это отдельная проблема.

Этот вопрос могут решить не только лингвисты, которые занимаются языкознанием. Давно сложились школы преподавания языка специальности: когда у нас в МГИМО учат иностранному языку, то обязательно преподается и язык специальности. Возможно, этот опыт можно перенести в лингвистику, связанную с развитием и использованием русского языка. Наши французские коллеги выпускают словари для различных профессиональных сфер. Есть достижения в сфере иноязычной лингвистики у славянских стран: они умеют защищать свои языки, имеют опыт существования национальных языков в межвоенный период, и многое из этого опыта мы можем взять.

В-третьих, это проблемы сохранения и развития переводческой школы. Мы можем много рассказать нашим французским коллегам о наших переводческих школах. Во Франции, в силу ее включенности в западноевропейский контекст, ее органической близости к языкам соседей, переводческая школа формировалась иначе, нежели в России.

Сегодня отечественная переводческая школа, к сожалению, размывается социально-экономическим контекстом. Без школы перевода невозможно работать с современной аудиовизуальной продукцией и словарями. Посмотрите на качество словарей, особенно профессиональных, которые можно найти в общедоступных поисковых системах. Если общеупотребительная лексика представлена здесь в целом неплохо, то в профессиональной лексике один англицизм заменяется другим, уже отчасти адаптированным, написанным на кириллице. Аведь количество читателей, которые пользуются словарями, изданными в солидных издательствах с привлечением высококвалифицированных специалистов несопоставимо с количеством интернет-читателей. В этой связи хотелось бы отметить и важность стимулирования рынка печатной продукции на том пространстве, которое по-прежнему доступно для русского языка. Можно сколько угодно говорить о российском влиянии, но, если вы не можете перевезти качественную книжную продукцию (учебную, научную, художественную литературу) на русском языке даже в соседнюю страну, то достичь цели будет трудно. Вопросы подготовки специалистов перевода - это проблема нормальной языковой подготовки, прежде всего школьных учителей. Противостоять внешнему языковому влиянию можно только тогда, когда ты знаешь, чему противостоишь. Без изучения иностранного языка это просто невозможно. 
Deuxièmement, il arrive souvent que la langue n'évolue pas comme nous le souhaiterions, subissant des influences extérieures. Une langue ne peut pas s'adapter à toute une série d'influences extérieures dans des domaines professionnels étroits, en particulier dans ceux qui se développent rapidement : la banque, la finance, la logistique. Ces domaines sont négligés par les linguistes. Allumez n'importe quelle chaîne, une radio business, sans parler des médias spécialisés, qui sont largement présents sur Internet : souvent, il faudra beaucoup d'efforts pour traduire du russe en russe et supprimer des jargonismes qui sont généralement basés sur l'anglais. Il est clair que ces communautés qui se développent de façon dynamique ne peuvent pas le faire elles-mêmes. Nous n'avons pas beaucoup de linguistes qui pourraient le faire, donc la modification d'une langue professionnelle est un problème à part.

Ce problème peut être résolu non seulement par les linguistes qui s'occupent de la langue russe. Depuis longtemps, il existe des écoles d'enseignement de la langue de la profession : lorsque nous, au MGIMO, enseignons une langue étrangère, la langue de la profession est obligatoirement enseignée. Peut-être cette expérience peut-elle être transférée dans la linguistique étudiant l'évolution et l'utilisation de la langue russe. Par exemple, nos collègues français publient des dictionnaires pour différents domaines professionnels. Nous pouvons également regarder l'expérience d'autres pays slaves dans le développement de la linguistique qui étudie des langues étrangères : ils savent protéger leurs langues, ils ont une expérience en matière de développement des langues nationales dans l'entredeux-guerres, et nous pouvons reprendre une grande partie de cette expérience.

Nous pouvons dire beaucoup de choses à nos collègues français sur les écoles de traduction. En France, en raison de son intégration dans le contexte de l'Europe occidentale et de sa proximité organique avec les langues de ses voisins, l'école de traduction ne s'est pas formée de la même façon qu'en Russie. Malheureusement, l'école de traduction russe s'érode sous l'influence du contexte socio-économique. Mais cela ne signifie pas qu'il n'y a pas besoin d'une école de traduction. Sans elle, il est impossible de travailler avec des produits audiovisuels modernes, avec des dictionnaires modernes. Aujourd'hui, un dictionnaire sur un support papier a un nombre d'utilisateurs tout à fait différent. Regardez la qualité des dictionnaires, surtout professionnels, présents dans des moteurs de recherche d'accès général : leur vocabulaire est très pauvre. Si le lexique général y est assez bien représenté, dans le lexique professionnel on voit qu'un anglicisme est remplacé par le même anglicisme, mais partiellement adapté, écrit en cyrillique. Ainsi, les enjeux de la formation des spécialistes en matière de traduction automatique, pour la sphère audiovisuelle, sont les enjeux de la préservation et du développement de l'école de traduction dans le pays et de la formation linguistique de qualité, tout d'abord, pour les professeurs d'école. Résister à une influence extérieure n'est possible que dans le cas où l'on sait à quoi l'on résiste. Sans l'apprentissage d'une langue étrangère, c'est tout simplement inimaginable.

La dernière chose que je voudrais évoquer est la stimulation du marché des livres et des produits textuels dans l'espace encore accessible pour la langue russe. Vous pouvez parler autant que vous voulez de l'influence russe, mais si vous ne pouvez pas, en tant qu'opérateur du marché du livre, transporter des livres à bas prix même vers un pays voisin, alors ces problèmes subsisteront. 